\title{
The Behavioural Neurology Assessment
}

\author{
S. Darvesh, L. Leach, S. E. Black, E. Kaplan, M. Freedman
}

\begin{abstract}
Background: We present information regarding the standardization, reliability and clinical validity of two versions of the Behavioural Neurology Assessment (BNA). The BNA-Long Form consists of 24 subtests within separate domains: Attention, Memory, Language, Visuospatial Function, Executive Function, and Praxis. The BNA-Short Form consists of 13 subtests within the domains of Attention, Memory, Naming, Visuospatial Function and Executive Function. In addition to individual domain indices, a Grand Total score was calculated for both BNA versions. Objective: To standardize the administration and scoring and validate the BNA for detection of dementia. Methods: Standardized normative data were obtained on 115 healthy subjects ranging in age from 50 to 95 . Testretest stability was obtained on 19 subjects and clinical validity was investigated by administering the BNA and Mini-Mental Status Examination (MMSE) to 29 patients with dementia and 29 age-matched healthy subjects (controls). Results: Age had a significant effect on all but the Visuospatial and Praxis indices of the BNA-Long Form and an effect on Naming and Grand Total score of the Short-Form. Internal consistency (Cronbach's coefficient $\alpha$ ) was .87 and .67 for the Long and Short Forms (.95 and .96 for dementia and control groups combined). Test-retest stability was acceptable. Grand Total indices of both BNA versions showed significant, positive correlations with the MMSE. Both BNA versions had superior sensitivity to dementia relative to the MMSE (.93 versus .79). Specificity was equivalent to the MMSE (.93 versus .97). Conclusions: Positive predictive values of the BNA and MMSE are equivalent but the BNA provides superior negative predictive value.
\end{abstract}

RÉSUMÉ: L'évaluation neurologique comportementale. Introduction: Nous discutons de la standardisation, de la fiabilité et de la validité clinique de deux versions différentes de l'évaluation neurologique comportementale (ÉNC). La version longue de l'ÉNC est constituée de 24 sous-tests dans différentes sphères: l'attention, la mémoire, le langage, la fonction visuospatiale, la fonction exécutive et la praxie. La version courte est constituée de 13 sous-tests dans les sphères de l'attention, de la mémoire, de la dénomination, de la fonction visuospatiale et de la fonction exécutive. En plus des indices pour chaque sphère, un score global a été calculé pour les deux versions de l'ÉNC. Objectif: Standardiser l'administration et l'évaluation de l'ÉNC et valider ce test pour la détection de la démence. Méthodes: Des données normatives standardisées ont été obtenues chez 115 sujets sains dont l'âge variait de 50 à 95 ans. La stabilité test-retest a été évaluée chez 19 sujets et la validité clinique chez 29 sujets déments et 29 témoins sains, appariés pour l'âge, à qui on a administré l'ÉNC et le MMSE. Résultats: En ce qui concerne la version longue de l'ÉNC, l'âge avait une influence significative sur tout sauf sur les indices visuospatiaux et la praxie et dans la version courte, il avait une influence significative sur le langage et sur le score global. La cohérence interne (coefficient de Cronbach a) était de 0,87 et 0,67 pour la version longue et la version courte respectivement $(0,95$ et 0,96 pour les groupes déments et témoins combinés). La stabilité test-retest était acceptable. Le score global pour les deux versions de l'ÉNC avait une corrélation positive significative avec le MMSE. Les deux versions de l'ÉNC avaient une sensibilité supérieure pour la démence relativement au MMSE (0,93 versus 0,79). La spécificité était équivalente à celle du MMSE (0,93 versus 0,97). Conclusions: Les valeurs prédictives positives de l'ÉNC et du MMSE sont équivalentes. Cependant, l'ÉNC a une valeur prédictive négative supérieure.

Can. J. Neurol. Sci. 2005; 32: 167-177

Mental status examination is used to aid clinical diagnosis of diseases affecting cognitive function. A commonly used test is the Mini-Mental Status Examination (MMSE). ${ }^{1}$ The MMSE is brief and convenient, features that are particularly attractive to both patients and clinicians. ${ }^{2}$ However, the ability of the MMSE to evaluate specific domains of cognitive functioning is limited by its brevity. There are several other cognitive tests that are more comprehensive than the MMSE, ${ }^{3-10}$ including the Mattis Dementia Rating Scale (DRS) and Modified Mini-Mental State Exam (3MS) that were designed to probe individual domains of functioning. The relative diagnostic efficiency of the MMSE and $3 \mathrm{MS}$ were reviewed by Tombaugh et $\mathrm{al}^{11}$ and the diagnostic efficiency of the MMSE and DRS were reviewed by Stuss et al. ${ }^{7}$

There are several well-established formal neuropsychological batteries that assess a broad spectrum of cognitive deficits ${ }^{12,13}$ but these are not suited for assessment by physicians in their office. To address this issue, we developed "The Behavioural Neurology Assessment" (BNA) designed for use by physicians

From the Departments of Medicine (Neurology and Geriatric Medicine), and Anatomy \& Neurobiology, Dalhousie University (SD), Halifax, NS, Canada; Department of Psychology (LL, EK), Rotman Research Institute (SEB, MF), Behavioural Neurology Program (MF), Baycrest Centre For Geriatric Care; Department of Medicine, Division of Neurology, Mount Sinai Hospital and University Health Network (MF), Sunnybrook and Women's College Health Science Centre (SEB), Department of Medicine (Neurology), University of Toronto (SEB, MF), Toronto, ON, Canada; Department of Psychology, Suffolk University and Departments of Neurology and Psychiatry, Boston University School of Medicine (EK), Boston, MA

ReCEIVED MARCh 26, 2003. ACCEPTED In FINAL FORM JANUARY 7, 2005. Reprint requests to: Morris Freedman, Division of Neurology, Baycrest Centre For Geriatric Care, Posluns Building, Room 656, 3560 Bathurst Street, Toronto, Ontario, Canada M6A 2E1 
as a mental status examination in the ambulatory or inpatient setting and that is reasonably brief to administer, covers the major cognitive domains and provides qualitative as well as quantitative information. Moreover, administration of the BNA requires only pencil and paper as opposed to test materials that are part of formal neuropsychological batteries. Our objectives were to: (1) standardize the administration and scoring of the BNA, (2) determine the effect of age and education on BNA variables, (3) determine the stability and reliability of the BNA, (4) determine the convergent validity of the BNA compared to the MMSE and (5) determine the ability of the BNA to discriminate dementia. The BNA was designed to be intermediate in length between the MMSE and a full neuropsychological battery.

\section{METHODS}

\section{Test Description - Long Form}

The BNA (Long Form) consists of 24 subtests divided into the following cognitive domains: Attention, Memory, Language, Visuospatial Function, Executive Function, and Praxis. The scale composition and points allotted for each subtest and scale of the Long Form domains are given in Table 1. They all had face validity and could be administered using only pencil and paper.

Attention Scale. This scale consists of five subtests. The Digit Span subtest consists of two subtests, digit span forwards and backwards. Both forwards and backwards digit spans consist of seven sets of digits ranging from two to eight digits. Each series is given one point for correct recitation. In the Continuous Performance Test, a series of random letters is read aloud to the participant who is requested to strike the table with her/his hand whenever the letter "A" occurs. The Serial Subtractions subtest consists of a set of three serial subtraction tasks that require the participant to count backwards by $7 \mathrm{~s}, 3 \mathrm{~s}$ and finally, $1 \mathrm{~s}$. The Backwards subtest consists of two subtasks. The first requires the participant to recite the months of the year in reverse order and the second requires recitation of the days of the week in reverse order.

Memory Scale. This scale consists of six subtests. The Orientation subtest requires the participant to produce the following information: date, month, year, day of week, season, place of testing, name of the province, current Prime Minister of Canada and Premier of the province in which the testing is taking place. The Immediate Verbal Recall subtest consists of three words that are read aloud and then immediate recall is requested. The Delayed Verbal Recall is timed to occur at least five minutes after the Immediate Verbal Recall; the participant is asked to recall the three words that were given before. If the participant fails to recall any word then a semantic category cue is given. Finally, if any words are not recalled after the category cue then the participant is asked to choose the word from a list of three words. The score for the Immediate Verbal Recall is based on three points for each word recalled (maximum $=9$ points). The score for the Delayed Verbal Recall is based on three points for spontaneous (uncued) recall, two points for cued recall and one point for correct recognition. The Immediate Visual Recall subtest consists of a set of three designs. The participant is asked
Table 1: Individual cognitive domains and scores in the Behavioural Neurology Assessment-Long Form

\begin{tabular}{|c|c|c|}
\hline \multirow{6}{*}{$\begin{array}{l}\text { Domain Index } \\
\text { Attention }\end{array}$} & Subtests & Score \\
\hline & Digit span forward & 7 \\
\hline & Digit span backward & 7 \\
\hline & Continuous performance test & 5 \\
\hline & Serial subtraction tests: $7 \mathrm{~s}, 3 \mathrm{~s} \& 1 \mathrm{~s}$ & 6 \\
\hline & Months, days backwards & 4 \\
\hline \multicolumn{2}{|l|}{ Maximum Score } & 29 \\
\hline \multicolumn{3}{|l|}{ Memory } \\
\hline & Orientation & 10 \\
\hline & Immediate verbal recall & 9 \\
\hline & Delayed verbal recall & 9 \\
\hline & Immediate visual recall & 15 \\
\hline & Delayed visual recall & 15 \\
\hline & Remote memory & 10 \\
\hline \multirow{6}{*}{$\begin{array}{l}\text { Maximum Score } \\
\text { Language }\end{array}$} & & 68 \\
\hline & & \\
\hline & Auditory comprehension & 14 \\
\hline & Repetition & 6 \\
\hline & Confrontation naming & 20 \\
\hline & Word generation - animal names & 20 \\
\hline \multirow{5}{*}{$\begin{array}{l}\text { Maximum Score } \\
\text { Visuospatial Function }\end{array}$} & & 60 \\
\hline & & \\
\hline & Draw a cube & 9 \\
\hline & Free drawn clock & 15 \\
\hline & Copy figures & 15 \\
\hline \multirow{7}{*}{$\begin{array}{l}\text { Maximum Score } \\
\text { Executive Function }\end{array}$} & & 39 \\
\hline & & \\
\hline & Similarities & 10 \\
\hline & Proverbs & 4 \\
\hline & Frontal motor & 11 \\
\hline & Word generation $-\mathrm{F}$ words & 20 \\
\hline & Oral calculations & 4 \\
\hline \multirow{3}{*}{$\begin{array}{l}\text { Maximum Score } \\
\text { Praxis }\end{array}$} & & 49 \\
\hline & & \\
\hline & Dominant hand praxis & 5 \\
\hline Maximum Score & & 5 \\
\hline Grand Total Score & & 250 \\
\hline
\end{tabular}

to copy the set of designs (the score of which will be used in the Copy Figures subtest of the Visuospatial Scale to be described below) and, following removal of the designs and copy, is then asked to reproduce the designs from memory. After at least a five-minute delay, the Delayed Visual Recall is conducted and the design is reproduced again from memory. The Remote Memory subtest consists of a set of ten famous people or events that the participant is asked to identify.

Language Scale. This scale consists of four subtests. In the Auditory Comprehension subtest, the participant is requested to carry out a set of five verbally administered, one-step commands; answer a set of five yes/no questions and carry out a 
set of five two-step commands. The Repetition subtest requires the participant to repeat a set of six phrases that vary in length from a single word to a complete sentence. In the Confrontation Naming subtest the participant is asked to name a set of 20 items; ten items are high-frequency and ten items are low frequency. The items are commonly found objects, not pictures, including items of clothing, glasses and body parts. For the Word Generation - Animal Names subtest, the participant is asked to generate animal names for one minute. Each animal name generated is awarded one point. However, to eliminate excessive weighting on this test, a maximum of 20 points is allowed.

Visuospatial Scale. This scale consists of three subtests. The participant is asked to reproduce a three-dimensional cube in the Draw a Cube subtest. In the Free Drawn Clock subtest, the participant is requested to produce a drawing of a clock that indicates 11:10. The Copy Figures subtest consists of the copy of the design utilized in the Immediate Visual Recall subtest described above.

Executive Function Scale. This scale consists of five subtests. The Similarities subtest consists of five, two-item word lists; the participant is asked to identify the similarities between each of the two items. The Proverbs subtest requires the subject to interpret two proverbs. The Frontal Motor subtest consists of three tasks, Alternating Sequences, Multiple Loops and $M$ and Ns. In each task of the Frontal Motor subtest, the participant is required to repetitively reproduce a design or symbol on paper. In the Word Generation - F Words subtest, the participant is given one minute to generate as many words as possible that begin with the letter "F". As with the Word Generation Animal Names subtest, a maximum of 20 points is allowed.

Praxis Scale. This scale consists of a single test of ideomotor praxis. The participant is asked to carry out a set of five actions. Three items are transitive actions that require miming the use of an object (e.g., "Show me how you would hammer a nail.") and two items are intransitive gestures (e.g., "Show me how you would wave goodbye.") The actions are performed with the dominant hand.

Grand Total. In addition to scores for each scale, the scale scores were summed to obtain a total of 250 points.

\section{Test Description - Short Form}

Preliminary analysis of the data after administration of the Long Form helped to identify items that exhibited good discrimination between individuals with and without dementia. Based on this analysis, we extracted subtest items that comprised the Short Form. The BNA Short Form consisted of 13 subtests divided into the following domains: Attention, Memory, Naming, Visuospatial Function, and Executive Function. The scale composition and point allotment for each subtest and scale of the Short Form are given in Table 2.

Attention Scale. This scale consists of three tasks, the serial subtraction by $7 \mathrm{~s}$ and $3 \mathrm{~s}$ and the months backwards that were used in the Long Form.

Memory Scale. This scale consists of three subtests. The Orientation subtest requires the subject to produce the following
Table 2: Individual cognitive domains and scores in Behavioural Neurology Assessment-Short Form

\begin{tabular}{|c|c|c|}
\hline Domain Index & Subtest & Score \\
\hline \multicolumn{3}{|l|}{ Attention } \\
\hline & Serial subtractions: $7 \mathrm{~s} \& 3 \mathrm{~s}$ & 4 \\
\hline & Months backwards & 2 \\
\hline Maximum Score & & 6 \\
\hline \multicolumn{3}{|l|}{ Memory } \\
\hline & Year & 1 \\
\hline & Month & 1 \\
\hline & Day & 1 \\
\hline & Date & 1 \\
\hline & Place & 1 \\
\hline & Prime Minister & 1 \\
\hline & Premier & 1 \\
\hline & Immediate verbal recall & 9 \\
\hline & Delayed verbal recall & 9 \\
\hline Maximum Score & & 25 \\
\hline \multicolumn{3}{|l|}{ Naming } \\
\hline & Confrontation Naming & 10 \\
\hline & Word generation - animal names & 20 \\
\hline Maximum Score & & 30 \\
\hline \multicolumn{3}{|l|}{ Visuospatial Function } \\
\hline & Free drawn clock & 15 \\
\hline Maximum Score & & 15 \\
\hline \multicolumn{3}{|l|}{ Executive Functions } \\
\hline & Similarities & 10 \\
\hline & Proverbs & 4 \\
\hline & Multiple loops & 2 \\
\hline & Alternating sequences & 2 \\
\hline & Word generation $-\mathrm{F}$ words & 20 \\
\hline Maximum Score & & 38 \\
\hline Grand Total Score & & 114 \\
\hline
\end{tabular}

information; date, month, year, day of week, place of testing, name of the current Prime Minister of Canada and Premier of the province in which the testing is taking place. The Immediate Verbal Recall and Delayed Verbal Recall subtests are the same as described above for the Long Form.

Naming Scale. This test consists of two subtests. The Confrontation Naming subtest consists of 10 items taken from the Confrontation Naming subtest of the Long Form. The Word Generation - Animal Names subtest is identical to the Long Form version.

Visuospatial Scale. This scale consists of a single item, the Free Drawn Clock representing 11:10.

Executive Scale. This scale consists of five subtests. The Similarities, Proverbs and Word Generation - F Words subtests are identical to those of the Long Form. In addition, Alternating Sequences and Multiple Loops, two items from the Long Form Frontal Motor subtest, are included. 
Grand Total. The individual domain scores were summed to obtain a BNA Short Form total of 114 points.

In both the Long and Short Forms, memory and verbal fluency were more heavily weighted due to their effectiveness at identifying Alzheimer's disease and other forms of dementia. ${ }^{14}$ The BNA-Long and Short versions, as well as the scoring sheets, comprise "supplementary material" and are available at the following website: www.baycrest.org.

All items constituting the BNA Long and Short Forms, including the 12 items on the MMSE, ${ }^{1}$ were printed in individual booklets, along with instructions for administration. Thus, each subject was administered the MMSE, as well as the BNA Long and Short Forms during the same testing session. The scores for the items that comprised the BNA Long Form, BNA Short Form and the MMSE were taken from the common administration protocol and summed to obtain the scores for each of the three tests.

Normative Sample. The normative sample consisted of 115 volunteers. They were recruited by advertising at Baycrest Centre for Geriatric Care in Toronto, Canada, following approval by the institutional ethics committee. After obtaining consent, a brief questionnaire about medical history was administered. Subjects were excluded if they had a history of neurological disease (e.g., stroke, seizures, head injury, encephalitis, meningitis, or suspected neurodegenerative disease), alcoholism, drug abuse, or psychiatric disease. Subjects were not excluded if English was their second language (ESL) unless they were unable to reliably understand the instructions and questions. The inclusion of ESL subjects was considered necessary to make the sample representative of the clientele seen in our clinic. The normative sample was subdivided into four age groups: 50-59, 60-69, 70-79 and $80+$ years.

Standardization/reliability studies. The BNA and MMSE were administered using standard instructions to all individuals in the normative study. Means and standard deviations were obtained for all BNA variables for each age group. To determine test stability, the BNA was administered a second time (approximately six weeks later) to a subgroup of 19 healthy subjects who participated in the normative study. To determine internal consistency reliability of both forms, Cronbach's coefficient $\alpha$ was calculated for the normative sample data as well as for the combined data of the normal control group and the dementia group. Cronbach's $\alpha$ provides an estimate of the overall homogeneity of test items by determining the correlation of each item with the total test score. Cronbach's $\alpha$ was calculated for items against the Grand Total as well as items within each individual subtest of the BNA Long and Short Forms.

Table 3: Demographic variables in subjects with dementia

\begin{tabular}{lccccc}
\hline Clinical diagnosis & $\begin{array}{c}\text { Average age } \\
\text { (years } \pm \text { s.d.) }\end{array}$ & Number of subjects & Males: Females & $\begin{array}{c}\text { MMSE } \\
\text { (mean } \pm \text { s.d.) }\end{array}$ & $\begin{array}{c}\text { Education } \\
\text { (years } \pm \text { s.d.) }\end{array}$ \\
AD & $74 \pm 6.0$ & 18 & $7: 11$ & $17.2 \pm 5.0$ & $12 \pm 4.0$ \\
$\mathrm{VaD}$ & $68 \pm 9.3$ & 6 & $5: 1$ & $23.2 \pm 7.9$ & $11 \pm 5.5$ \\
$\mathrm{AD} / \mathrm{VaD}$ & $70 \pm 4.2$ & 2 & $1: 1$ & $19.0 \pm 11.3$ & $12 \pm .7$ \\
FTD & $75 \pm 7.1$ & 2 & $1: 1$ & $20.5 \pm 5.0$ & $10 \pm 1.1$ \\
Other & 86 & 1 & 1 & 18 \\
\hline
\end{tabular}

$\mathrm{AD}=$ Alzheimer's disease, $\mathrm{VaD}=$ vascular dementia, $\mathrm{FTD}=$ fronto-temporal lobar degeneration

Table 4: Demographic variables of normative study subjects

\begin{tabular}{|c|c|c|c|c|}
\hline \multirow[b]{2}{*}{ Demographic Variable } & \multicolumn{4}{|c|}{ Age (years) } \\
\hline & $50-59$ & $60-69$ & 70-79 & $80+$ \\
\hline Sample size & 19 & 29 & 35 & 32 \\
\hline Age (years \pm s.d.) & $55.6 \pm 2.8$ & $65.1 \pm 2.8$ & $74.1 \pm 2.7$ & $83.3 \pm 3.4$ \\
\hline Education (years \pm s.d.) & $13.2 \pm 2.5$ & $13.5 \pm 2.4$ & $12.5 \pm 2.3$ & $13.5 \pm 3.5$ \\
\hline MMSE (mean \pm s.d.) & $29.0 \pm 1.3$ & $28.7 \pm 1.3$ & $28.1 \pm 2.1$ & $28.1 \pm 1.6$ \\
\hline \multicolumn{5}{|l|}{ Gender } \\
\hline Male & 7 & 13 & 12 & 15 \\
\hline Female & 12 & 16 & 23 & 17 \\
\hline \multicolumn{5}{|l|}{ Handedness } \\
\hline Right & 19 & 28 & 31 & 31 \\
\hline Left & 0 & 1 & 3 & 1 \\
\hline Ambidextrous & 0 & 0 & 1 & 0 \\
\hline ESL* & 2 & 2 & 4 & 8 \\
\hline
\end{tabular}

\footnotetext{
* English as second language
} 
Table 5: Behavioural Neurology Assessment: Long Form Normative Data: Mean test score $\pm 95 \%$ confidence intervals ${ }^{\mathrm{a}}$ and reliability

\begin{tabular}{|c|c|c|c|c|c|c|}
\hline \multirow{2}{*}{ Test Variable } & \multicolumn{4}{|c|}{ Age Groups } & \multirow{2}{*}{$\mathbf{F}(3,111)$} & \multirow[b]{3}{*}{ Reliability } \\
\hline & & & & \multirow[b]{2}{*}{$80+$} & & \\
\hline & $50-59$ & $60-69$ & 70-79 & & $\mathbf{p}$ & \\
\hline \multirow[t]{2}{*}{ Attention } & 23.5 & 21.0 & 21.8 & 20.9 & 3.19 & .53 \\
\hline & \pm 4.4 & \pm 3.9 & \pm 4.3 & \pm 4.6 & .03 & \\
\hline \multirow[t]{2}{*}{ Memory } & 62.8 & 60.6 & 59.0 & 54.4 & 4.30 & .70 \\
\hline & \pm 6.4 & \pm 7.6 & \pm 9.4 & \pm 12.4 & .007 & \\
\hline \multirow[t]{2}{*}{ Language } & 58.4 & 54.9 & 54.5 & 53.9 & 4.29 & .70 \\
\hline & \pm 1.9 & \pm 3.3 & \pm 6.1 & \pm 5.5 & .007 & \\
\hline \multirow[t]{2}{*}{ Visuospatial Function } & 36.0 & 34.9 & 34.0 & 34.6 & .93 & .71 \\
\hline & \pm 3.2 & \pm 4.1 & \pm 4.2 & \pm 5.1 & $\mathrm{~ns}$ & \\
\hline \multirow[t]{2}{*}{ Executive Function } & 41.5 & 38.4 & 37.7 & 35.8 & 3.30 & .59 \\
\hline & \pm 4.9 & \pm 5.6 & \pm 8.9 & \pm 9.5 & .023 & \\
\hline \multirow[t]{2}{*}{ Praxis } & 5.0 & 4.8 & 4.7 & 4.8 & 1.05 & .54 \\
\hline & \pm .3 & \pm .7 & \pm .8 & \pm .5 & $\mathrm{~ns}$ & \\
\hline \multirow[t]{2}{*}{ Grand Total } & 227.0 & 214.4 & 211.9 & 204.5 & 4.83 & .87 \\
\hline & \pm 9.5 & \pm 9.3 & \pm 15.3 & \pm 18.9 & .003 & \\
\hline
\end{tabular}

Confidence intervals based on standard error of measurement (SEM) calculated as $S E M=s d(1-\mathrm{r})^{1 / 2}$ where $s d=$ standard deviation of sample and $r=$ reliability estimate. ${ }^{\mathrm{b}}$ Reliability based on Cronbach's $\alpha$ except for Praxis which is based on test-retest reliability.

Convergent validity/clinical discriminability study. To determine the clinical utility of the BNA (Long and Short Forms), the results from clinical examinations of 29 patients referred to the Behavioural Neurology Clinic at Baycrest Centre for Geriatric Care were obtained. All 29 patients had undergone independent neurological and neuropsychological evaluations and, as a result, had been determined to have cognitive impairment that met Diagnostic and Statistical Manual of Mental Disorders, Fourth Edition, criteria for dementia. ${ }^{15}$ The BNA and MMSE were not used in diagnosing dementia. Demographic characteristics and clinical diagnoses of the dementia group are presented in Table 3. Each subject in the dementia group was matched for age and education to a healthy subject (control) from the normative study. Both groups were administered the BNA and MMSE. Convergent validity was determined by calculating individual correlation coefficients between the MMSE and both forms of the BNA.

\section{Results}

\section{Standardization Study}

The demographic characteristics along with the mean MMSE scores for each age group in the standardization study are given in Table 4. The age groups did not differ with respect to either mean level of education or to proportion of individuals with English as a second language. The group of ESL individuals had a mean education of $11.4(\mathrm{SD}=3.2)$ years and the group in which English was the first language had a mean education of 13.4 $(\mathrm{SD}=2.6)$ years; this difference in education level between the two groups was significant $(\mathrm{t}(113)=2.76, \mathrm{p}<.01)$. Education and ESL were significantly correlated with the MMSE score $(\mathrm{r}(113)=.31, \mathrm{p}<.01$ and $\mathrm{r}(113)=-.27, \mathrm{p}<.01)$. Although age was significantly correlated with the MMSE score $(r(113)=-.25$, $\mathrm{p}<.01$ ), the mean MMSE scores between the age groups was not significantly different.

BNA - Long Form. The mean test variable scores and 95\% confidence intervals for each of the four age groups are presented in Table 5. The results of a multivariate analysis of variance (MANOVA) revealed that age had a significant, albeit small, effect on the Attention $\left(\mathrm{F}(3,111)=3.19, \mathrm{p}=.03, \eta^{2}=.08\right)$, Memory $\left(\mathrm{F}(3,111)=4.30, \mathrm{p}=.007, \eta^{2}=.10\right)$, Language $\left(\mathrm{F}(3,111)=4.29, \mathrm{p}=.007, \eta^{2}=.10\right)$, Executive Function $\left(\mathrm{F}(3,111)=3.30, \mathrm{p}=.023, \eta^{2}=.08\right)$ and Grand Total $(\mathrm{F}(3,111)=$ $4.83, \mathrm{p}=.003, \eta^{2}=.12$ ) scores. Age did not have a significant effect on Visuospatial Function or Praxis scores. With respect to differences in Grand Total score between age groups, only the difference between the youngest (50-59) and oldest (80+) age groups was significant at the .05 level.

Education was significantly correlated with the Long Form Grand Total score $(\mathrm{r}(113)=.33, \mathrm{p}<.001)$. We analysed the effect of education for the ESL subjects and for those whose first language was English. First, ESL was also significantly correlated with the Grand Total score $(\mathrm{r}(113)=-.28, \mathrm{p}<.01)$. As a group, subjects with ESL obtained a significantly lower Grand Total score $[$ mean difference $=27.31, \mathrm{~F}(1,113)=30.86, \mathrm{p}<.01$, Cohen's $d=1.40$ ] relative to the subjects who spoke English as a first language.

The BNA Long Form demonstrated good internal consistency. Cronbach's coefficient $\alpha$ between the individual item scores and the Grand Total score of the Long Form was .87. Cronbach's $\alpha$ for the individual items comprising each subtest of the Long Form ranged from .50 to .71 (mean $=.63$ ). The 
Table 6: Behavioural Neurology Assessment-Long Form test-retest reliability

\begin{tabular}{|c|c|c|c|c|c|}
\hline \multirow[b]{2}{*}{ Test Variable } & \multicolumn{2}{|c|}{ Mean Score \pm s.d. } & \multirow[b]{2}{*}{$\mathbf{t}(18)$} & \multirow[b]{2}{*}{ Effect size $^{a}$} & \multirow[b]{2}{*}{$\mathbf{r}(\mathbf{1 8})$} \\
\hline & First test & Second test & & & \\
\hline Attention & $23.7 \pm 3.9$ & $23.2 \pm 3.0$ & .69 & .15 & $.61^{* *}$ \\
\hline Memory & $62.7 \pm 5.2$ & $64.6 \pm 4.3$ & 1.66 & .36 & .45 \\
\hline Language & $55.4 \pm 4.5$ & $56.6 \pm 3.7$ & 1.29 & .28 & $.48^{*}$ \\
\hline Visuospatial Function & $35.7 \pm 2.8$ & $36.7 \pm 2.6$ & 1.97 & .43 & $.66^{* *}$ \\
\hline Executive Function & $41.7 \pm 4.2$ & $42.7 \pm 4.4$ & 1.24 & .27 & $.70^{* *}$ \\
\hline Praxis & $4.8 \pm .4$ & $4.8 \pm .7$ & .00 & .00 & $.54 *$ \\
\hline Grand Total & $224.1 \pm 11.0$ & $228.7 \pm 11.9$ & $2.44^{*}$ & .54 & $.74 * *$ \\
\hline
\end{tabular}

$* \mathrm{p}<.05 ; * * \mathrm{p}<.01 ;{ }^{\text {a Cohen's } d}$

reliabilities for the individual Long Form subtests are given in Table 5.

The modest reliabilities reported above could have resulted from a restricted range of scores obtained by the neurologically normal individuals. To determine the reliability of a wider range of scores, Cronbach's $\alpha$ was calculated using the combined control and dementia groups from the discrimination validity study. Cronbach's $\alpha$ for individual items and the Grand Total score of the Long Form was .95. The internal consistency reliabilities for the subtests of the Long Form were: Attention $\alpha$ $=.76$, Memory $\alpha=.86$, Language $\alpha=.81$, Visuospatial $\alpha=.77$, Executive $\alpha=.89$. (Cronbach's $\alpha$ for the Praxis subtest of the Long Form could not be calculated because it consisted of a single item.)

Long Form test-retest stability data are presented in Table 6. Test-retest reliabilities for the Long Form subtest scores varied from .45 to .70 . The test-retest reliability of the Long Form Grand Total score was .74 $(95 \% \mathrm{ci}=.43-.89)$. Except for the Memory scores, all first and second scores were significantly correlated at the .05 levels. Test session had a significant effect on the mean Grand Total score; no other test-retest mean differences were significant, indicating that BNA scores remained stable over time.

BNA - Short Form. The mean variable scores and the 95\% confidence intervals for each of the four age groups are presented in Table 7. A MANOVA indicated that age had a significant effect on the Naming $(\mathrm{F}(3,111)=4.94$, $\mathrm{p}$ $\left.=.003, \eta^{2}=.12\right)$, and Grand Total $(\mathrm{F}(3,111)=4.45, \mathrm{p}=$ $\left..005, \eta^{2}=.11\right)$ scores. Age did not have a significant effect on the Attention, Memory, Visuospatial Function or Executive Function variable scores. The mean Short Form Grand Total of the 50-59 year-old group was significantly higher $(\mathrm{p}<.05)$ than the $70-79$ and $80+$ group.

Education was significantly correlated with the Short Form Grand Total score $(\mathrm{r}(113)=.34, \mathrm{p}<.01)$. English as a second language was also significantly correlated with the Short Form Grand Total score $(\mathrm{r}(113)=-.30, \mathrm{p}<.01)$. As a group, subjects with ESL obtained a significantly lower Short Form Grand Total score [mean difference = 14.12, $\mathrm{F}(1,113)=26.65, \mathrm{p}<.01$, Cohen's $\mathrm{d}=1.38]$ relative to the non-ESL group.
As would be expected from a shorter test, the BNA Short Form demonstrated lower reliability than the BNA Long Form; Cronbach's $\alpha$ of .67 for the BNA Short Form Grand Total score was modest. The brevity of the Short Form subtests tended to result in lower reliabilities compared to the Long Form subtests: Cronbach's $\alpha$ for the individual items comprising each subtest of the Short Form ranged from .11 to .64 (mean = .45). The reliabilities of the individual subtests are presented in Table 7.

The internal consistency of the Short Form items was higher when a wider range of scores was considered by combining the data of control and dementia groups. Cronbach's $\alpha$ for individual Short Form items and the Grand Total score was .96. The internal consistency reliabilities for the subtests of the Short Form were: Attention $\alpha=.85$, Memory $\alpha=.92$, Naming $\alpha=.85$, Executive $\alpha=.86$. (Cronbach's $\alpha$ for the Visuospatial subtest of the Short

Table 7: Behavioural Neurology Assessment: Short Form normative data: Mean test score $\pm 95 \%$ confidence intervals ${ }^{a}$ and reliability ${ }^{b}$

\begin{tabular}{lcccccc}
\hline & \multicolumn{7}{c}{ Age Groups } & & F(3,111) \\
\cline { 2 - 5 } Test Variable & $\mathbf{5 0 - 5 9}$ & $\mathbf{6 0 - 6 9}$ & $\mathbf{7 0 - 7 9}$ & $\mathbf{8 0}+$ & $\mathbf{p}$ & Reliability \\
Attention & 5.2 & 4.9 & 4.7 & 4.9 & .64 & .59 \\
& \pm 1.5 & \pm 1.8 & \pm 1.5 & \pm 1.9 & $\mathrm{~ns}$ & \\
Memory & 23.8 & 23.7 & 23.5 & 22.3 & 2.41 & .11 \\
& \pm 3.5 & \pm 3.9 & \pm 4.4 & \pm 5.2 & $\mathrm{~ns}$ & \\
Naming & 28.8 & 25.7 & 25.5 & 24.8 & 4.94 & .64 \\
\multirow{2}{*}{ Visuospatial Function } & \pm 2.0 & \pm 3.4 & \pm 5.2 & \pm 5.3 & .003 & \\
& \pm 2.3 & 13.9 & 13.5 & 13.6 & .84 & .36 \\
Executive Function & 31.6 & 28.6 & 28.4 & 27.3 & 2.47 & .48 \\
\multirow{2}{*}{ Grand Total } & \pm 5.1 & \pm 6.4 & \pm 8.6 & \pm 9.0 & $\mathrm{~ns}$ & \\
& 103.7 & 96.7 & 95.7 & 93.0 & 4.45 & .67 \\
& \pm 6.8 & \pm 6.9 & \pm 13.0 & \pm 15.1 & .005 &
\end{tabular}

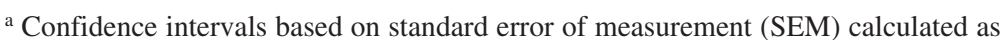
$S E M=s d(1-\mathrm{r})^{1 / 2}$ where $s d=$ standard deviation of sample and $\mathrm{r}=$ reliability estimate. b Reliability based on Cronbach's $\alpha$ except for Visuospatial which is based on testretest reliability. 
Table 8: Behavioural Neurology Assessment-Short Form: Test-retest reliability

\begin{tabular}{lcccccc}
\hline & \multicolumn{2}{c}{ Mean Score \pm s.d. } & & & \\
Test Variable & First test & Second test & t(18) & Effect size & r(18) \\
Attention & $5.6 \pm .7$ & $5.1 \pm 1.0$ & 1.76 & .39 & .27 & .14 \\
Memory & $23.7 \pm 2.2$ & $24.4 \pm 1.1$ & 1.23 & .02 & $.62^{*}$ \\
Naming & $26.6 \pm 2.8$ & $26.9 \pm 3.6$ & .40 & .76 & .36 & $.76^{* *}$ \\
Visuospatial Function & $13.8 \pm 1.0$ & $14.6 \pm .6$ & $3.44^{* *}$ & .32 & .42 & $.77^{* *}$ \\
Executive Function & $31.4 \pm 4.1$ & $32.4 \pm 4.2$ & 1.44 & 1.92 & & \\
Grand Total & $101.2 \pm 6.6$ & $103.4 \pm 7.7$ & & & \\
\end{tabular}

$* \mathrm{p}<.05 ; * * \mathrm{p}<.01 ;{ }^{\mathrm{a}}$ Cohen's $d$

Table 9: Comparison of performance on Behavioural Neurology Assessment-Long Form by control subjects and individuals with dementia

\begin{tabular}{|c|c|c|c|c|c|}
\hline \multirow[b]{2}{*}{ Test Variable } & \multicolumn{2}{|c|}{ Mean Score \pm s.d. } & \multirow[b]{2}{*}{$F(1,56)$} & \multirow[b]{2}{*}{$\mathbf{p}$} & \multirow[b]{2}{*}{ Effect size $^{\text {a }}$} \\
\hline & Control & Dementia & & & \\
\hline Attention & $21.3 \pm 3.2$ & $13.1 \pm 5.0$ & 56.6 & $<.001$ & 1.95 \\
\hline Memory & $57.1 \pm 9.8$ & $29.9 \pm 14.2$ & 72.6 & $<.001$ & 2.21 \\
\hline Language & $54.2 \pm 4.3$ & $39.0 \pm 11.3$ & 46.0 & $<.001$ & 1.76 \\
\hline Visuospatial Function & $34.1 \pm 4.2$ & $19.6 \pm 9.9$ & 52.4 & $<.001$ & 1.88 \\
\hline Executive Function & $38.0 \pm 6.1$ & $17.3 \pm 10.7$ & 82.1 & $<.001$ & 2.35 \\
\hline Praxis & $4.8 \pm .6$ & $3.9 \pm 1.7$ & 8.0 & $<.01$ & .73 \\
\hline Grand Total & $209.5 \pm 19.8$ & $122.6 \pm 44.6$ & 91.8 & $<.001$ & 2.48 \\
\hline
\end{tabular}

a Cohen's $d$

Table 10: Comparison of the performance on Behavioural Neurology Assessment-Short Form by control subjects and individuals with dementia

\begin{tabular}{lccccc}
\hline & \multicolumn{2}{c}{ Mean Score \pm s.d. } & & & \\
\cline { 2 - 3 } Test Variable & Control & Dementia & F(1,56) & p & Effect size $^{\mathbf{a}}$ \\
Attention & $4.8 \pm 1.5$ & $1.6 \pm 1.8$ & 58.4 & $<.001$ & 1.98 \\
Memory & $23.1 \pm 2.8$ & $16.0 \pm 5.4$ & 39.7 & $<.001$ & 1.63 \\
Naming & $25.1 \pm 3.4$ & $14.8 \pm 6.2$ & 61.4 & $<.001$ & 2.03 \\
Visuospatial Function & $13.8 \pm 2.0$ & $8.0 \pm 4.5$ & 40.1 & $<.001$ & 1.64 \\
Executive Function & $29.0 \pm 5.3$ & $13.3 \pm 8.6$ & 69.8 & $<.001$ & 2.16 \\
Grand Total & $95.8 \pm 9.4$ & $53.6 \pm 22.3$ & 88.4 & $<.001$ & 2.44
\end{tabular}

a Cohen's $d$

Form could not be calculated because it consisted of a single item.) Thus, when the reliabilities were calculated on a sample with greater range of scores, acceptable reliability measures were obtained on all Short Form measures.

Test-retest stability data of the Short Form are presented in Table 8. Test session had a significant effect on the Visuospatial Function score. There were no other significant differences between first and second test scores for any of the remaining variables. Test-retest reliabilities for the Short Form subtests ranged from .02 to .76. Test-retest reliability for the Short Form Grand Total score was $.77(95 \%$ ci $=.49-.91)$. Significant test- retest correlations were obtained for the Naming, Executive Function, and Grand Total variable scores.

\section{Clinical Validation Study}

The results of a MANOVA comparing mean variable scores between the dementia and control groups for the BNA Long Form, as well as the Short Form, are shown in Tables 9 and 10. There was a significant group effect for the Long Form [Wilk's $\Lambda=.325, \mathrm{~F}(7,50)=14.83, \mathrm{p}<.001, \eta^{2}=.68$ ] as well as the Short Form [Wilk's $\Lambda=.361, F(7,50)=18.41, \mathrm{p}<.001, \eta^{2}=$ .64]. Compared to the control group, the dementia group 
Table 11: Distribution of Cutoff Scores for BNA Long Form

\begin{tabular}{lcrrrccc}
\hline Score & Sn & Sp & PPA & NPA & LRPR & LRNR & CC \\
154 & .69 & 1.00 & 1.00 & .76 & $\infty$ & .31 & .84 \\
158 & .72 & .97 & .95 & .78 & 21.00 & .29 & .84 \\
160 & .76 & .97 & .96 & .80 & 22.00 & .25 & .86 \\
162 & .76 & .97 & .96 & .80 & 22.00 & .25 & .86 \\
168 & .79 & .93 & .92 & .82 & 11.50 & .22 & .86 \\
174 & .83 & .93 & .92 & .84 & 12.00 & .19 & .88 \\
178 & .86 & .93 & .93 & .87 & 12.50 & .15 & .90 \\
182 & .93 & .93 & .93 & .93 & 13.50 & .07 & .93 \\
186 & .97 & .86 & .88 & .96 & 7.00 & .04 & .91 \\
194 & .97 & .83 & .85 & .96 & 5.60 & .04 & .90 \\
200 & .97 & .79 & .82 & .96 & 4.67 & .04 & .88 \\
204 & 1.00 & .76 & .81 & 1.00 & 4.14 & .00 & .88
\end{tabular}

Abbreviations: $\mathrm{Sn}=$ sensitivity; $\mathrm{Sp}=$ specificity; $\mathrm{PPA}=$ positive predictive ability; NPA = negative predictive ability; LRPR = likelihood ratio of a positive result; $\mathrm{LRNR}=$ likelihood ratio of a negative result; $\mathrm{CC}=$ correct classification .

Table 12: Distribution of Cutoff Scores for BNA Short Form

\begin{tabular}{lcrrrrrr}
\hline Score & Sn & Sp & PPA & NPA & LRPR & LRNR & CC \\
70 & .76 & 1.00 & 1.00 & .81 & $\infty$ & .24 & .88 \\
72 & .76 & .97 & .96 & .80 & 22.00 & .25 & .86 \\
78 & .83 & .93 & .92 & .84 & 12.00 & .19 & .88 \\
80 & .90 & .93 & .93 & .90 & 13.00 & .11 & .91 \\
82 & .93 & .93 & .93 & .93 & 13.50 & .07 & .93 \\
84 & .93 & .90 & .90 & .93 & 9.00 & .08 & .91 \\
86 & .93 & .86 & .87 & .93 & 6.75 & .08 & .90 \\
92 & .97 & .79 & .82 & .96 & 4.67 & .04 & .88 \\
94 & .97 & .72 & .78 & .95 & 3.50 & .05 & .84 \\
96 & .97 & .59 & .70 & .94 & 2.33 & .06 & .78 \\
98 & 1.00 & .52 & .67 & 1.00 & 2.07 & .00 & .76
\end{tabular}

Abbreviations: $\mathrm{Sn}=$ sensitivity; $\mathrm{Sp}=$ specificity; $\mathrm{PPA}=$ positive predictive ability; NPA = negative predictive ability; LRPR = likelihood ratio of a positive result; LRNR = likelihood ratio of a negative result; $\mathrm{CC}=$ correct classification.

obtained significantly lower mean scores $(\mathrm{p}<.05)$ on all subtests of both versions of the BNA.

The dementia group obtained a mean MMSE score of 19.1 ( $\mathrm{SD}=6.3$; range 6 - 30) and the control group obtained a mean MMSE score of 28.2 ( $\mathrm{SD}=1.5$; range $24-30$ ). The mean difference between the groups was significant, $(\mathrm{t}(56)=7.59, \mathrm{p}<$ .001, Cohen's d = 2.74).

Cut-off scores were estimated by comparing the distribution of the Grand Total scores of the dementia and control groups for both the BNA Long and Short Forms. Optimal cut-off scores were established by determining the Grand Total score that maximized correct classification of the dementia and control groups. A cut-off Grand Total score of 182 on the Long Form correctly classified 93 percent of the sample $\left(\chi^{2}(1, \mathrm{~N}=58)=\right.$ $43.10, \mathrm{p}<.01)$. On the Short Form, a Grand Total score of 82 correctly classified 93 percent of the sample $\left(\chi^{2}(1, \mathrm{~N}=58)=\right.$ $43.10, \mathrm{p}<.01)$. The range of scores used to determine the cutoffs for the BNA Long and Short Form are given in Tables 11 and 12. The range includes the highest scores obtained by the dementia group and the lowest scores obtained by the normal control group. These scores can be used as the "rule-out" and "rule-in" scores respectively. For example, to rule out dementia one would want to obtain a score that exceeds the highest score obtained by the dementia group. Conversely, to rule in dementia would require a score lower than the lowest score obtained by the normal control group.

To compare the relative diagnostic effectiveness of the BNA to the MMSE, the optimal cut-off score for the MMSE was calculated. As was done for the BNA forms, the optimal MMSE cut-off score was established by determining the score that maximized correct classification of the dementia and control groups. A total MMSE cut-off score of 26 correctly classified 88 percent of the sample $\left(\chi^{2}(1, \mathrm{~N}=58)=34.40, \mathrm{p}<.01\right)$. The relative discriminatory efficiencies of both forms of the BNA and the MMSE are given in Table 13. Both versions of the BNA were more sensitive than the MMSE although both BNA forms and MMSE exhibited equivalent specificity. The positive predictive abilities of the BNA Long Form, Short Form, and MMSE were approximately equivalent but the negative predictive abilities of both BNA forms were superior to the MMSE. The likelihood ratios for the MMSE and both forms of the BNA are also given in Table 13. The likelihood ratio represents the odds that a given diagnostic test result (either positive or negative) would be expected in an individual with dementia. The MMSE has a superior positive likelihood ratio although the negative likelihood ratio of either BNA form is superior to that of the MMSE.

In order to appreciate the relative discriminatory abilities of

Table 13: Discrimination of control vs dementia group on Behavioural Neurology Assessment - Long and Short Forms vs MMSE

\begin{tabular}{|c|c|c|}
\hline $\begin{array}{c}\text { BNA - Long } \\
182 \\
\end{array}$ & $\begin{array}{c}\text { Test } \\
\text { BNA - Short } \\
82 \\
\end{array}$ & $\begin{array}{l}\text { MMSE } \\
26 \\
\end{array}$ \\
\hline $\begin{array}{c}.93 \\
(.78-.98) *\end{array}$ & $\begin{array}{c}.93 \\
(.78-.98)\end{array}$ & $\begin{array}{c}.79 \\
(.62-.90)\end{array}$ \\
\hline $\begin{array}{c}.93 \\
(.78-.98)\end{array}$ & $\begin{array}{c}.93 \\
(.78-.98)\end{array}$ & $\begin{array}{c}.97 \\
(.83-.99)\end{array}$ \\
\hline $\begin{array}{lc}\text { Positive Predictive } & .93 \\
\text { Ability } & (.78-.98)\end{array}$ & $\begin{array}{c}.93 \\
(.78-.98)\end{array}$ & $\begin{array}{c}.96 \\
(.80-.99)\end{array}$ \\
\hline $\begin{array}{lc}\text { Negative Predictive } & .93 \\
\text { Ability } & (.78-.98)\end{array}$ & $\begin{array}{c}.93 \\
(.78-.98)\end{array}$ & $\begin{array}{c}.82 \\
(.66-.92)\end{array}$ \\
\hline $\begin{array}{r}\text { Correct Classification } .93 \\
(.87-1.00)\end{array}$ & $\begin{array}{c}.93 \\
(.87-1.00)\end{array}$ & $\begin{array}{c}.88 \\
(.80-.96)\end{array}$ \\
\hline $\begin{array}{l}\text { Likelihood ratio for } 13.50 \\
\text { positive result } \quad(3.53-51.61)\end{array}$ & $\begin{array}{c}13.50 \\
(3.53-51.61)\end{array}$ & $\begin{array}{c}23.00 \\
(3.32-159.23)\end{array}$ \\
\hline $\begin{array}{l}\text { Likelihood ratio for } \quad .07 \\
\quad \text { negative result } \quad(.02-.28)\end{array}$ & $\begin{array}{c}.07 \\
(.02-.28)\end{array}$ & $\begin{array}{c}.21 \\
(.10-.44)\end{array}$ \\
\hline
\end{tabular}

* Numbers in parentheses represent $95 \%$ confidence intervals 


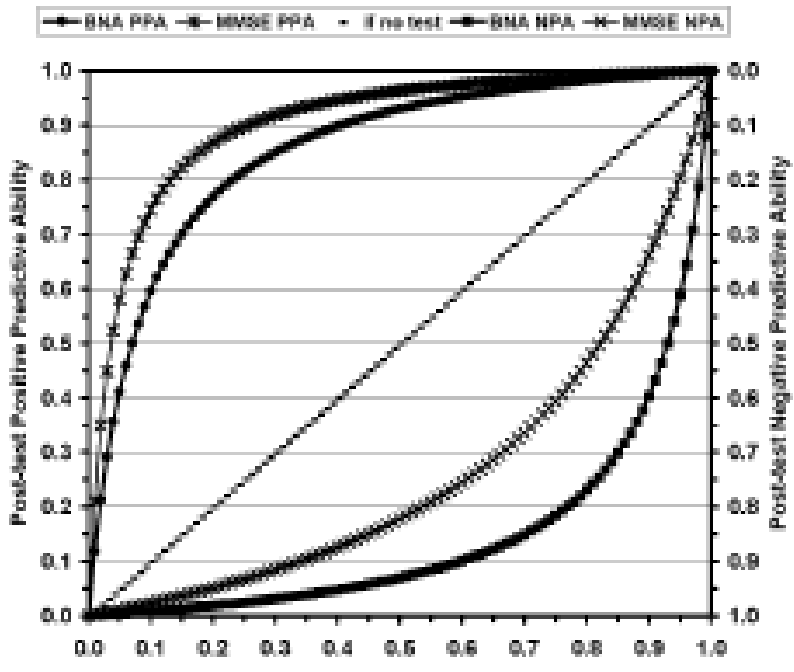

Pre-test Probability (Prevalence)

Figure 1: Comparison of BNA and MMSE dementia prediction as a function of prevalence. BNA sensitivity $=.93$, specificity $=.93 ; \mathrm{MMSE}$, sensitivity $=.79$, specificity $=.97$. Note the reversal of the right $y$ axis for the plotting of negative predictive ability

tests it is also necessary to consider the effects of prevalence, or base-rate, of a disease on the tests' diagnostic ability. If sensitivity and specificity are held constant, then as prevalence of disease increases the positive predictive ability increases but the negative predictive ability decreases. Conversely, as prevalence decreases, negative predictive ability increases and positive predictive ability decreases. This can best be appreciated by plotting positive and negative abilities of a test against prevalence. The plots of both positive and negative predictability of the optimal cut-off scores of the BNA and MMSE as a function of prevalence are presented in the receiver operating characteristic curve (ROC) in Figure 1. Given that the BNA Long and Short Forms had identical sensitivities and specificities, only one curve is plotted for both forms. Utilizing the generated ROC, it is possible to make predictions about the relative clinical efficiency of tests at different prevalence levels. Based on predictions from our sample, the BNA and MMSE have equivalent positive predictive value for groups or settings where the prevalence of dementia is above .5. On the other hand, the MMSE exhibited slightly better positive predictive ability when prevalence was below .5. Our validation study revealed that both forms of the BNA were superior to the MMSE with respect to negative predictive ability at moderate to high levels of prevalence (e.g., .5) and higher. For example, for a prevalence of $.5,17.8 \%$ of the demented group obtained an MMSE score above the cut-off (i.e., would have falsely been identified as normal) but only $7 \%$ of the demented group obtained a BNA score above the cut-off. At a prevalence of $.8,46.4 \%$ of clients with dementia would be expected to obtain a "normal" MMSE score but in comparison, $23.1 \%$ of clients with dementia would obtain a "normal" BNA score. Therefore, in a memory clinic, where the likelihood of seeing clients with dementia is high, the BNA would miss $50 \%$ fewer clients with dementia relative to the MMSE.
Convergent validity. The correlation between the BNA Long Form Grand Total scores and the MMSE scores was significant, $\mathrm{r}(113)=.70, \mathrm{p}<.01$. The Short Form Grand Total score and the MMSE were also significantly correlated, $\mathrm{r}(113)=.68, \mathrm{p}<.01$. Both BNA Long and Short Form Grand Total scores were significantly correlated with each other $(\mathrm{r}(113)=.90, \mathrm{p}<.01)$, as would be expected given that both forms share identical items.

\section{Discussion}

Utilizing standardized administration rules and scoring procedures, the BNA was administered to a group of 115 volunteers ranging in age from 50 to 92 years. Based on the normative sample, Long and Short Forms were developed. Age had an effect on measures obtained from both forms. Education was significantly correlated with total scores of both BNA forms but due to the small effect size no correction is required for interpreting the data. There was a significant effect for ESL but caution should be used when interpreting results obtained from individuals whose first language is not English.

The BNA Long Form demonstrated acceptable internal consistency but as would be expected with a shorter instrument, the BNA Short Form demonstrated lower, modest internal consistency overall. When individual subtests were considered, only modest internal consistency was obtained. Increasing the range of scores, by combining data from individuals with dementia and nondemented volunteers, resulted in substantially higher reliability estimates and thus reliabilities of the Grand Total scores of both forms were acceptable.

Test-retest reliability was acceptable for all BNA Long Form and most Short Form subtests, as well as for Grand Total scores of both long and short forms. Although the Grand Total score on the BNA Long Form exhibited a significant change over time, the mean change in Grand Total scores between first and second administrations of the Long Form was 4.6 out of a possible 250 points. On the Short Form, only the Visuospatial Function score exhibited a significant change; the mean change in Visuospatial Function scores between first and second administrations of the Short Form was only 0.8 out of a possible 15 points. The slight differences were significant due to the relatively small variance for the Grand Total score on the Long Form and for the Visuospatial Function score on the Short Form. Moreover, the mean change in the two test scores was smaller than the $95 \%$ confidence interval of either test. The finding of significant practice effect is a common phenomenon among many tests of intellectual and cognitive functioning and should always be taken into consideration when repeating the same test. Unfortunately the design of this study did not allow us to distinguish between true change and expected change on the BNA.

Compared to the MMSE, both versions of the BNA were superior for discriminating individuals with dementia from agematched normal control subjects. The BNA and MMSE have equivalent positive predictive value for groups or settings where the prevalence of dementia is above 0.5 . On the other hand, the MMSE exhibited slightly better positive predictive ability when prevalence was below 0.5. Both forms of the BNA were superior to the MMSE with respect to negative predictive ability at moderate to high levels of prevalence (e.g., 0.5 and higher). The superiority of the BNA is best appreciated by making projections 
based on the ROC curve (Figure 1). An example of how this information can be used can be taken from our own clinic. We receive referrals from primary care physicians and medical specialists with the most common referral question being the presence of a dementia. We estimate that $80 \%$ of our clients are diagnosed with some form of dementia following their investigations. For every 1000 clients seen in our clinics, the BNA is expected to identify 744 true positive cases of dementia. In comparison, the MMSE will identify only 632 true positive cases. Furthermore, for 1000 clients, the MMSE will miss (false negative) 168 cases of dementia while the BNA will miss only 56 cases; thus the BNA will identify 112 more cases. However, the BNA will yield 14 false positives whereas there will be six false positive cases using the MMSE. To further minimize the risk of false positives, lower cut-offs can be adopted. Reference to Tables 11 and 12 will enable the clinician to tailor the decision criteria to the specific needs of the situation.

We were able to compare directly only the BNA to the MMSE and demonstrated superiority of the BNA in terms of overall classification as well as negative prediction. In terms of administration time, the BNA falls between a brief screen such as the MMSE and a full neuropsychological battery, therefore more appropriate comparators to the BNA would be tests of similar duration such as the $3 \mathrm{MS}$ or the Mattis Dementia Rating Scale. A problem arises when attempting to compare tests across different studies due to the possibility that dementia severity may be very different. For example, Tombaugh and McIntyre ${ }^{5}$ reviewed the diagnostic characteristics of the MMSE across several studies. Considering the studies they reviewed that compared demented to cognitively intact subjects, sensitivity of the MMSE ranged from .54 to 1.00 and specificity ranged from .46 to 1.00 . There was an apparent relation between diagnostic accuracy and severity of cognitive impairment of the demented groups; the studies that reported the lowest mean MMSE score for demented groups obtained the highest sensitivity measures (e.g., mean MMSE $=10$, sensitivity $=1.00$, specificity $=1.00$ ). A similar outcome was obtained by Tombaugh et $\mathrm{al}^{11}$ who compared the clinical discrimination of the MMSE and 3MS in either mildly impaired or severely impaired patients with Alzheimer's disease (AD) versus cognitively intact patients. For mild AD, MMSE sensitivity was .81 and specificity was .77 (correct classification $=.79$ ) but for severe AD sensitivity was .96 and specificity was 1.00 (correct classification $=.98$ ). For the 3MS, sensitivity was .89 and specificity was .82 (correct classification $=.85$ ) for mild $\mathrm{AD}$ but for severe $\mathrm{AD}$ sensitivity was .86 and specificity was .96 (correct classification $=.90$ ). Considering that our group of dementia patients would be classified as mild (mean MMSE = 19.1), the classification rate for the BNA was better than that reported by Tombaugh et al ${ }^{11}$ for the $3 \mathrm{MS}$.

Stuss et $\mathrm{al}^{7}$ and Meiran et $\mathrm{al}^{6}$ compared the diagnostic accuracy of several tests including the DRS, as well as the MMSE. An advantage of these two studies was that the same groups of dementia patients and non-impaired patients were administered the same tests. Stuss et $\mathrm{al}^{7}$ reported that the standard DRS cut-off of 123/144 yielded a sensitivity of .72, specificity of .84 and classification accuracy of .76. Using a score of 136, Stuss et $\mathrm{al}^{7}$ found better overall classification of .83; although sensitivity was better (.95) specificity was lower
(.55). The overall mean MMSE score (20.2) for the dementia patients in the Stuss et $\mathrm{al}^{7}$ sample was comparable to our sample in severity, therefore the BNA obtained a superior classification of .93 relative to the DRS.

Compared to Stuss et $\mathrm{al}^{7}$ Monsch et ${ }^{1}{ }^{16}$ obtained better discrimination for detecting Alzheimer type dementia from nondemented clients for the DRS. Monsch et $\mathrm{al}^{16}$ reported that a cutoff of 130/144 yielded a classification of .97 (sensitivity, .97; specificity, .99). They may have obtained better discrimination for the DRS than Stuss et $\mathrm{al}^{7}$ did because their reported mean DRS score of 100.9 for the dementia group was considerably lower than the mean of 110.7 obtained by the Stuss et $\mathrm{al}^{7}$ dementia group. This suggests that when the severity of dementia is taken into consideration, the BNA is superior to the DRS in classification of dementia. Regardless of severity, the classification achieved by the BNA did not differ significantly, based on our confidence intervals (see Table 13), from the classification rate of the DRS reported by Monsch et al. ${ }^{16}$ For confirmation, future studies should make direct comparisons of the BNA to the DRS and the 3MS.

The BNA is well suited for settings where expected prevalence of dementia is high, such as in geriatric and memory disorders clinics. The Long Form of the BNA can take approximately 40-50 minutes to administer and is best suited for use in specialized clinics that focus on in-depth evaluation of cognitive function. In contrast, the Short Form takes approximately 20-30 minutes to administer and is better suited for a busy office setting. The individual subtests of the Long Form are more reliable than the Short Form, therefore the Long Form is the test of choice if the intent is to compare an individual's performance across cognitive domains. There is one final caveat about the use of the Short Form. We extracted the Short Form items from the same administration of the Long Form items. Therefore the validation of the Short Form was based on the Long Form rather than independent validation. When using the Short Form, the clinician has the option to supplement testing with items from the Long Form in a selective fashion based on the need for more information. In this way, the domains for the Long Form can be conceptualized as consisting of modules (e.g., language module) that can be used to supplement the Short Form as needed.

We have been utilizing the BNA to help triage clients for more extensive neuropsychological evaluations. Given that neuropsychological evaluations are more sensitive to cognitive change, but also lengthier, there was a need to reduce demand and wait time for neuropsychological assessments. We have been utilizing neuropsychological evaluations primarily in cases where clients have scored above the cut-off for dementia on the BNA. This minimizes the chance of missing cases of dementia which, based on the above calculations, would be 56 per 1000 clients for the BNA. To reduce the chance of false positive responses, we consider the lowest score obtained by nondemented individuals; by adopting this decision criterion, we minimize requests for further cognitive testing in cases where the likelihood of dementia is very high. We are currently evaluating the efficiency of using this two-tiered approach to dementia assessment. It will also be important to determine how well scores on the BNA predict who will progress to dementia and to compare the findings to those reported for the MMSE. ${ }^{17}$ 
Early identification of dementia is very important, especially given the increasing availability of treatments for dementias such as Alzheimer's disease. ${ }^{18-20}$ With the development of therapies to provide symptomatic treatment for dementia, coupled with the rapid growth of our knowledge in dementia, it is anticipated that therapies to slow, or even halt, the progression of diseases producing cognitive impairment will become available. Consequently, tests of mental state that correctly identify individuals with dementia are greatly needed. The BNA in its Long and Short Forms provides one method to better identify individuals with dementia, and to rule out change in cognition due to normal aging so that available therapies can be implemented in a timely fashion. In cases where further comprehensive evaluation for neurocognitive status is required, a referral to a neuropsychologist may enable refinement of diagnosis, as well as recommendations for therapeutic rehabilitation.

Supplementary Content available at www.baycrest.org: Behavioural Neurology Assessment (BNA)-Long version and scoring sheet, Behavioural Neurology Assessment (BNA)-Short version and scoring sheet

\section{ACKNOWLEDGEMENTS}

During the preparation of this manuscript, Dr. S. Darvesh held grants from the New Brunswick Heart and Stroke Foundation, The Scottish Rite Charitable Foundation of Canada and the Queen Elizabeth II Health Sciences Centre Research Fund, Halifax, Nova Scotia. Dr. M. Freedman held grants from the Medical Research Council of Canada, Ontario Mental Health Foundation, and Canadian Institutes of Health Research and was supported by the Saul A. Silverman Family Foundation, Toronto, Ontario, Canada, as part of a Canada International Scientific Exchange Program (CISEPO) project. Dr. S. Black also acknowledges funding from Canadian Institutes of Health Research grant (MT13129).

Work presented in part at the 30th Canadian Congress of Neurological Sciences Meeting, Victoria, British Columbia, Canada, 1995

\section{REFERENCES}

1. Folstein MF, Folstein SE, McHugh PR. Mini-Mental State: a practical method for grading the cognitive state of patients for the clinician. J Psychiatr Res 1975; 12:189-198.

2. Shulman KI, Feinstein A. Quick Cognitive Screening for Clinicians: Mini Mental, Clock Drawing and other Brief Tests. London,
England: Martin Dunitz Publishers, 2003.

3. Kiernan RJ, Mueller J, Langston JW, Van Dyke C. The Neurobehavioral Cognitive Status Examination: a brief but quantitative approach to cognitive assessment. Ann Int Med 1987; 107:481-485.

4. Schwamm LH, Van Dyke C, Kiernan RJ, Merrin EL, Mueller J. The Neurobehavioral Cognitive Status Examination: comparison with the Cognitive Capacity Screening Examination and the MiniMental State Examination in a neurosurgical population. Ann Int Med 1987; 107:486-491.

5. Tombaugh TN, McIntyre NJ. The Mini-Mental State Examination: a comprehensive review. J Am Geriatr Soc 1992; 40:922-935.

6. Meiran N, Stuss DT, Guzman DA, Lafleche G, Willmer J. Diagnosis of dementia: methods for the interpretation of scores of 5 neuropsychological tests. Arch Neurol 1996; 53:1043-1054.

7. Stuss DT, Meiran N, Guzman DA, Lafleche G, Willmer J. Do long tests yield a more accurate diagnosis of dementia than short tests? A comparison of 5 neuropsychological tests. Arch Neurol 1996; 53:1033-1039.

8. Mathuranath PS, Nestor PJ, Berrios GE, Rakowicz W, Hodges JR. A brief cognitive test battery to differentiate Alzheimer's disease and frontotemporal dementia. Neurology 2000; 55:1613-1620.

9. Dubois B, Slachevsky A, Litvan I, Pillon B. The FAB: a frontal assessment battery at bedside. Neurology 2000; 55:1621-1626.

10. Teng EL, Chui HC. The Modified Mini-Mental State (3MS) examination. J Clin Psychiatry 1987; 48:314-318.

11. Tombaugh TN, McDowell I, Kristjansson B, Hubley AM. MiniMental State Examination (MMSE) and the Modified MMSE (3MS): A Psychometric Comparison and Normative Data. Psychol Assess 1996; 8: 48-59.

12. Lezak MD. Neuropsychological assessment,. 3rd ed. New York: Oxford University Press, 1995.

13. Strub RL, Black FW. The Mental Status Examination in Neurology, 3rd ed. Philadelphia: FA Davis Company, 1993.

14. Zakzanis KK, Leach L, Kaplan E. Neuropsychological Differential Diagnosis. Lisse, Netherlands: Swets \& Zeitlinger, 1999.

15. DSM-IV. Diagnostic and Statistical Manual of Mental Disorders. 1994. Washington, DC, American Psychiatric Association.

16. Monsch AU, Bondi MW, Salmon DP, et al. Clinical validity of the Mattis Dementia Rating Scale in detecting dementia of the Alzheimer type. Arch Neurol 1995; 52: 899-904.

17. Hogan DB, Ebly EM. Predicting who will develop dementia in a cohort of Canadian Seniors. Can J Neurol Sci 2000; 27:18-24.

18. Grutzendler J, Morris JC. Cholinesterase inhibitors for Alzheimer's disease. Drugs 2001; 61:41-52.

19. Giacobini E. From molecular structure to Alzheimer therapy. Jpn J Pharmacol 1997; 74:225-241.

20. Krall WJ, Sramek JJ, Cutler NR. Cholinesterase inhibitors: a therapeutic strategy for Alzheimer disease. Ann Pharmacother 1999; 33:441-450. 